\title{
Gender Equality and Social Inclusion in Technical and Vocation Education and Training
}

\author{
Shiba Bagale \\ Trainer \\ Community Development Programme \\ Training Institute for Technical Instruction (TITI) \\ Sanothimi, Bhaktapur, Nepal \\ Email for correspondence:sbd@ titi.org.np or shiba@kusoed.edu.np
}

\begin{abstract}
This study is about the present scenario of Gender Equality and Social Inclusion GESI in the technical schools. This study has tried to explore the present scenario, how the schools are mainstreaming in GESI and how is GESI mainstreaming done in the schools. This study is qualitative in nature and the interview was done with three female and one male participant who have been working in the schools. The participants experience and perception is carried out in the study through the in-depth interview. The study shows that there are several improvements in the GESI field and most of the schools have GESI unit which seems good for the implementation of the policies formulated regarding the GESI. Also this study has tried to dig out the GESI barriers in the mainstreaming and implementation level in the local level. Though there are many changes, many improvements, there are still chances to make it more effective and make GESI friendly environment in the school.
\end{abstract}

Keywords: Gender, gender equality, social inclusion, GESI mainstreaming and barriers

\section{Introduction}

Gender Equality and Social Inclusion (GESI) is one of the cross-cutting issues in every sector. Gender is defined as the state of being male and female. It refers to the cultural and socially constructed between the sexes. Gender is not about something we are born with, and not about something we have, but it is about something we do (West and Zimmerman 1987) and something we perform (Butler 1990). Sex refers to the natural and biological differences between male and female. So it is biological and . is difficult to change. But gender is a social construct and gender roles depend upon the society and culture.

Social exclusion is the multi-dimensional concept and it is seen in every society. Walker and Walker (1997) define social exclusion as "Dynamic process of being shutout, partially or fully, from any of the social, economic, political, or cultural systems which determine the social integration of a person in society". So it has been the abjuration (or nonrealization) of the civil, political, and social rights of citizen of the country. Thus it is the opposite of social integration (de Haan, 1998). 
Social inclusion is distinct from social exclusion. It is the social integration or the social cohesion of the disadvantaged, marginalized, backward people, mostly the excluded people in the society. Social exclusion is defined as, "the removal of institutional barriers and the enhancement of incentives to increase the access of diverse individuals and groups to development opportunities" (Alsop, Bertelsen \& Holland, 2006). So the issues of GESI and its implementation has been one of the major challenges in society.

In the context of Nepal, we do have several cases of social exclusion, inclusion. There are inclusion policies, reservation and quotas system for the excluded groups to mainstream them in the social life and development process. The Constitution of Nepal, 2015 also has focused on the issues of GESI. It promises to end gender-based discrimination through proportional and inclusive participation of women. It allows for special provisions for socially and culturally disadvantaged women, and recognizes women's right to lineage without gender-based discrimination.

Millennium Development Goals (MDG) had also ensured the rights of gender and excluded groups which further are highlighted on Sustainable Development Goals (SDG) too. It also highlights on gender equality. SDG 5 is about achieving gender equality and empowering all women and girls. So it has been one of the major issues in the sector of development too.

Nepal has made significant progress in ensuring equal access to education, with gender parity in primary and secondary level school enrolment. But the discrimination and violence against women and girls remain despite substantial improvements. The proposed targets for 2030 include eliminating gender disparity in all levels of education, wage discrimination at similar work, physical and sexual violence, and all harmful practices, and raising the presence of women in the national parliament and public service decision-making positions (National Planning Commission, 2016). There are several rules, regulations, plans and policies to address the gender issues.

\section{Purpose of the Study}

The main purpose of the training was to explore the GESI scenario in the TVET sector. Furthermore, it aimed to highlight on how the GESI mainstreaming is done in TVET.

Research Questions

The main research questions of this study are:

1. What is the present scenario of GESI in the schools?

2. How are the schools focusing on GESI mainstreaming?

3. What are the challenges and barriers on GESI mainstreaming?

\section{Policy Review}

Regarding the GESI integration, there are several plans and policies in the government level as well as TVET sector. They are:

\section{TVET Policy, 2012}

TEVT policy highlights on providing the advantage to the real disadvantage groups. Significant changes have been made in recent years in results of the changed political environment. Nepal's laws constitution and civil code has continued to include the discriminatory provisions particularly in relation to citizenship, nationality, inheritance, ownership, marriage and family, employment and education which is also highlighted in TVET policy. TVET policy, (2012) focuses on youth and adult human resources who were taken out or not admitted to school, are illiterate or have not obtained any kind of skills either through TVET system. It has also highlighted on the access and inclusion of the poor, women, marginalized community.

The TVET Policy ,(2012) focuses on the five following areas; specific strategies have been drawn up to achieve each one of them:

i. expansion: to expand training opportunities and services;

ii. inclusion and access: to give access to training 
to all citizens in need and to ensure opportunity for receiving training to all;

iii. integration: to integrate various training modes and training providers into one system;

iv. quality and relevance: to link training contents and training outcomes with economic demands; and

v. funding: to ensure sustainable funding for technical education and vocational training.

The provisions for the differently able people should be highlighted. The tools to identify the excluded groups are needed within the policy. And if the implementation is done, it would have a better opportunity to provide justice to the needed ones. GESI sensitization programmes seem lacking in the policies which should be integrated in all the levels and courses. So practical and result oriented GESI tools and programmes are needed.

\section{Methodology}

This study is qualitative in nature. In this, I have focused on interpretive inquiry. One of the goals of the interpretivism is to comprehend and interpret human behaviour, so this paradigm has helped me to come up with different ideas while conducting my study. King, Keohane \& Verba (1994) say that this approach helps to ask the right question and even give additional conference in the conclusions.

The ethnographic study was done with the participants as ethnography mainly highlights the cultural observations of the study. Ethnography is an interpretive, reflexive and constructive process which can be done with the continuous inquiries (Whitehead, 2004). So it helped to explore the GESI culture in the school with this study. It helps to gain a comprehensive, complete picture of participants (Given, 2008). So it is the study of the people in the natural setting which has helped to obtain the information related to GESI and other GESI related issues. This has helped to obtain the multiple realities of the participants.

Marshall (2006), focuses on, "the value of the ethnographic interview lies in its focus on culture through the participant's perspective and through firsthand encounter which is especially useful for eliciting participants' meanings for events and behaviors and for generating a typology of cultural classification schemes"(p.104). To obtain the information, in-depth interview was conducted. The study is based on the in-depth interview with the participants who are the instructors of the technical schools of the CTEVT and working as GESI focal persons in the schools. There were altogether four participants in the study. Among them three were female and one was male. For the selection of the participants, purposive sampling was done.

\section{GESI in TVET}

Gender Equality and Social Inclusion (GESI) is the concept that addresses unequal power relation between women and men and between social groups that focuses on the need for action to rebalance these power relations, equal rights and respect for all individuals. GESI has been introduced in Technical and Vocational Education and Training (TVET) in one or another way. The first thing is that most of the female in the vocational training used to choose traditional trainings. But later on, women also started getting involved in non-traditional vocational training and community based training. But still the gender discrimination in the choosing of the different occupation exists. So, there exists gender segregation in technical and vocational education programme (Hartl, 2009).

Sudha (pseudonym), GESI focal person and agriculture assistant of a technical school said that she has seen several changes in the TVET sector with regards to the GESI issues from the past and now. She said that the female students who used to choose the traditional trade in the past are being lesser and now both the sexes are choosing nontraditional trades. So the number of female in the TVET sector is less than that of the male because of traditional beliefs (Ngure, 2013). So there is urgent need to add the trades. Also the number of trainees for the excluded group is increasing nowadays. 
Similarly, Saroj (pseudonym), GESI focal person and trade head of a technical school said that the changes are incomparable. He said that though there were some efforts in the beginning too but the issue was neglected and was not implemented but now the case has been sensitive and all the staffs are alert about using words and their behaviour. He further addeds, "Traditional mind set has been changed and Training and training centres are being GESI friendly". Tan, Tan and Young (2000) also points out that poverty and the social mindset are the main challenges to women for the entrepreneurship in TVET.

Likewise, Junu (pseudonym), Head of Department and GESI focal person of another technical school has said that, "Provision of Scholarship for dalits, female and marginalized has addressed GESI issues". She further added that the inclusive recruitment system has also been one of the good examples for the GESI implementation in the TVET sector. The scholarship scheme for the Disadvantaged Groups has also focused on the GESI mainstreaming, says, Balawati, an English instructor of another technical school. She is not the member of GESI unit. But she agrees on the necessity of the GESI unit. She further added that the social mindset has been changed and investment in non-traditional occupation for the daughters has been increased. People see these types of jobs as non-prestigious blue-collar employment (Teklehaimanot, 2002) which is one of the main aspects in the involvement of all types' gender, caste, people, and excluded groups in the TVET sector.

\section{GESI Mainstreaming in TVET}

Mainstreaming is an approach and strategy to empower some specific group or community. GESI mainstreaming is to engage and empower women and marginalized group. Mainstreaming is not the end but the means and strategy. GESI Mainstreaming refers to, " the process whereby barriers and issues of women and poor and excluded people are identified and addressed in all functional areas of infrastructure development system: policies, institutional systems, work environment and culture, programme and budget formulation, service delivery, monitoring and evaluation, and research" (Government of Nepal, 2013).

There are several plans and provisions to mainstream GESI in different organizations and development sectors. In the same way, the issue of GESI mainstreaming has been adopted in different technical schools of Nepal. For this, there are different programmes. Skills Development Project (SDP) is also implementing GESI programs for the Quality Improvement Programme (QIP) for selected technical schools. S. Bista (personal communication, 21 April, 2016, GESI consultant, SDP) said that, "we have different programmes for the GESI mainstreaming in QIP schools and there are several indicators which determine the progress of GESI mainstreaming in the schools".

For the GESI mainstreaming in different sector, different programmes and different policies are formulated. In these aspects, Sudha highlighted on the TVET policy 2012 which has also focused on the gender issues. Also she added that in the recruitment process in the schools, the GESI has been focused and the instructors are given priorities that are from the marginalized, excluded groups, women, poor etc. This shows that some efforts have been started in the root level.

But Saroj has some disagreement in the mainstreaming policies. He said that, "though there are good plans and policies but the implementation level is not enough". He also said that the mainstreaming schemes like scholarship for the needy people has been increased and provided but not in the fair competition, there are still some rumours". This also shows that there are chances to improve and maintain gender balance, social inclusion in the school level.

In the same way, Junu remembers that they had recruited the staffs on the base of fair competition, qualification and GESI integration. They have focused the minorities groups and female in the 
recruitment. Also she said that there are some issues that have been solved in the local level, such as the discrimination and harassment cases. She further added, "If there are any complaints about the GESI issues, then the GESI team would handle it and solve the problem with proper counselling and even punishment". But she was upset on saying that the issues are most of the time hidden or taken without seriousness; so it has been difficult to handle all the cases that happens within the school environment.

Likewise, Balawati, said that she is trying to change the students' mindset on different GESI issues. She said that some of the words, language the students used are not GESI friendly. So she is providing some extra inputs on those issues. She said that, "our school has very good provision on these types of issues". She further added, the school is trying to make it GESI friendly by adding some physical infrastructures, motivating both the students and teachers to use gender friendly language, to create GESI friendly environment. Eshetu (2014) has also a finding that the school physical infrastructure also hampers on the participation of women in TVET sector. This shows that there are plans and awareness about GESI mainstreaming in the school level.

\section{GESI Barriers in TVET}

To complete a single task, we face several barriers. So there are several barriers in the implementation and application level of any programmes and projects, plans and policies. So in mainstreaming GESI in the school level there are several barriers. The very most common and important barriers that we face in the GESI mainstreaming is the attitudinal barriers. Until and unless, the mindset of the people is changed and they feel the change is necessary, and then only the implementation would be effective.

Similarly, Sudha said that the social mindset of the people is one of the main barriers in the GESI mainstreaming. Similarly, she added that for the female, socially excluded groups, physically challenged, there is no safe accommodation, infrastructure in the schools like hostels, toilets, ramps etc which has also created the problem. Also the poor and marginalized students do not have enough money to study and also the scholarship is not sufficient for all the needy people. She also added, "The low prospect in the decent work and low self-confidence, fear of challenge in the peoples is another barrier". UNESCO (2009) also states that, in most poor countries (and in many rich), the general esteem of TVET is low. Until and unless, they realize and become confidence on what they are doing, they will face challenges and barriers in field.

Though there are barriers, there is a scope too. Junu believes on self-empowerment as the best way to fight against the barriers the people face in the life. But she also agrees on economic barrier for that poor and marginalized group to take a challenge. Likewise, she pointed out, "Some people do not have physical and mental abilities to compete with others; so GESI mainstreaming has been a challenge". One major thing she highlighted on, "lack of information dissemination for excluded, poor and marginalized groups to utilize their skills and knowledge, which is collapsing their opportunity to participate in different programmes". ILO (2008) also highlights this issue as most of the women in the developing countries are backward because of lack of information. It seems a serious matter that the needy people are not getting information and lacking the right to information.

Not only this, Saroj highlights on the discriminatory decisions, policies, plans, acts, rules and regulations. Also the curriculum is not gender friendly. The curriculum needs to be changed time and again as per the demand of the market. Middleton (1996) has also stated that, conducting periodical survey, annually or quarterly in the developing countries is the most way to attain information and identify organizational change in the economy, movement of relative wage and employment by skill qualification. He disagrees on the role of female participation only in the name of participation but do not have a role in decision making. He also added that lack of ownership has been another barrier on 
GESI mainstreaming.

Balawati blames on city centred academic institutions that are working for profit motive but not maintaining the code of conduct that they should. So she agrees on the social mindset and the behaviour of the people which is not providing the way to maintain GESI friendly environment in the workplace and every sector. She further added, "Traditional beliefs, rites and rules, gap in knowledge and information, language, geographical difficulties are also the barriers of GESI mainstreaming the local level". This shows that the proper information sharing, knowledge and the implementation authorities are also creating barriers.

In this regard, the most common ways out is to make the implementation effective. All the participants said that the GESI budget and GESI plan has to be maintained and implemented in an effective way. GESI focal persons and, GESI unit also should be made active in each and every aspect.

\section{Findings}

The major findings of the study is that the participants are aware about the GESI information and about maintaining GESI friendly environment but they are seeing challenges in the implementation level. There have been several changes in the GESI issues which are very positive aspect.

There is equal participation, equal government salary for all the staffs of same level. But the study shows that there is still discrimination on the types of job and the engagement of female on traditional occupation, which has been a serious issue .

Not only this, the school physical infrastructure are not GESI friendly. The school environment, accommodation and other facilities are not GESI friendly. Several initiations are done in the national level and school level. The scholarship provisions are also increased to the poor and the needy people that also include the gender and socially excluded groups. There are several targeted programmes for the mainstreaming of the GESI groups like inclusion policies.; GESI unit in the school and, GESI team have been active for making the GESI friendly environment. It also helps for the cases of harassment, solve the issues, makes decisions for the punishment etc. The school infrastructure are also being changed and in the process of making it GESI friendly. The school environment is also being improved from the past to present. Also the participation of women and socially excluded groups is being increased in several skills based trainings and non-traditional fields of skills and occupation.

During the staff recruitment, many schools have tried to maintain gender equality and had have prioritized female, socially backward, poor, marginalized and disadvantaged groups. Even during the student enrolment, the provisions of scholarship for the needy, excluded, poor etc are being highlighted to motivate them to study. Also the curriculum and the courses are not as per the need of the students to maintain the GESI. So curriculum should be developed to maintain entrepreneur skills (Ngure, 2013) in the GESI groups. There are several good things and improvement is seen. But still, a few things like planning, participation is seen less from the targeted groups. Also the plans and policies seem lacking in the implementation level.

\section{Implications}

The provision of GESI in the schools has been very effective for the targeted groups. With some small changes, there would be huge improvement in the local level. So some implications are highlighted below:

i. $\quad$ For overcoming obstacles in maintaining gender equality, the teachers could implement affirmative action in the schools.

ii. For the enhancement of the employees capabilities and assets to make GESI friendly school environment, school principals could apply the empowerment strategies, capacity building strategies.

iii. All the concerned and stakeholders should be GESI friendly and should be committed in both words and works and all of them 
should try to include all the excluded in the equity basis.

\section{References}

Alsop, R., Bertelsen, M.F., \& Holland, J. (2006). Empowerment in Practice: From Analysis to Implementation. The World Bank: Washington D.C.

Butler, J. (1993). Bodies that matter.New York: Routledge. Retrieved from http://eng5010. pbworks.com/f/ButlerBodiesThatMatterEx.pdf

de Haan, A. (1998). Social exclusion: An alternative concept for the study of deprivation? IDS Bulletin. doi: 10.1111/j.1759-5436.1998.mp29001002.x

Eshetu, H. (2014). Participation of female students in technical and vocational training in entoto technical and vocational education and training poly technic college: implications for gender equity. A master's Thesis, Addis Ababa University. Retrieved from http://etd.aau.edu.et/bitstream /123456789/7201/1/1.HaimanotEshetu.pdf

Given, L. M. (2008). Qualitative research methods. In The Encyclopedia of Educational Psychology, edited by Neil J. Salkind, 827-831. Thousand Oaks, CA: Sage Publications.

Government of Nepal. (2010). Gender Equality and Social Inclusion operational guidelines, 2013. Ministry of Urban Development. Retrieved from http://www.moud.gov.np/acts-regulations/GESI Guidelines-en.pdf

Government of Nepal. (2012). TVET Policy. Kathmandu :Author.

Hartl, M. (2009). Technical and vocational education and training (TVET) and skills development for poverty reduction - do rural women benefit? Retrieved from http://citeseerx.ist.psu.edu /viewdoc/download?doi=10.1.1.464.7649\& rep=rep $1 \&$ type $=$ pdf
ILO . (2008). Women Entrepreneurs in Kenya. Factors affecting Women Entrepreneurs in Micro and Small Enterprises in Kenya. Geneva. International Labor Organization.

Marshall, C. (2006). Data Collection Methods. Retrieved from https://www.sagepub.com/sites/ default/files/upm-binaries/10985_Chapter_4.pdf

Middleto, J. (1996). Skill for productivity. New York: Oxford University Press.

National Planning Commission. (2016). Retrieved from http://www.npc.gov.np/images/ download/23rd_Jan_final_for_print_ Sustainable_Development_Goals.pdf)

Ngure, S.W. (2012). Stakeholders' perceptions of technical, vocational education and training: the case of Kenyan micro and small enterprises in the motor vehicle service and repair industry. Thesis of Doctorate of Philosophy, Edith Cowan University. Retrieved from http://ro.ecu.edu.au/cgi/viewcontent.cgi? article $=1598 \&$ context $=$ theses

Tan, T., Tan, W., \& Young, E. (2000).Entrepreneurial Infrastructure in Singapore: Developing a Model and Mapping Participation. Journal of Entrepreneurship. Vol. 9, No. 1.doi: 10.1177/ 097135570000900101

Teklehaimanot, H. (2002). Misconceptions of technical and vocational education and training in Ethiopia. Institute of educational research. Flambeau, 10(1),1-15.Document, Kenya. September 2003.

UNESCO. (2009). Strategy on technical and vocational education and training (TVET). International consultation meeting on TVET. Bonn .Retrieved from http://www.unevoc. unesco.org/fileadmin/user_upload/docs/ ReportTVETStrategyMeetingBonn_01.pdf 
Walker, A. \& Walker, C. (1997) (Eds.) Britain Divided: The Growth of Social Exclusion in the 1980s and 1990. London: CPAG.

West, C. \& Zimmerman, D. (1987). Doing gender.

Gender and Society 1, pp. 125-151, doi: 10.1177/0891243287001002002

Whitehead, T.L. (2004). What is Ethnography? Retrieved from http://www.cusag.umd.edu /documents /workingpapers/epiontattrib.pdf 